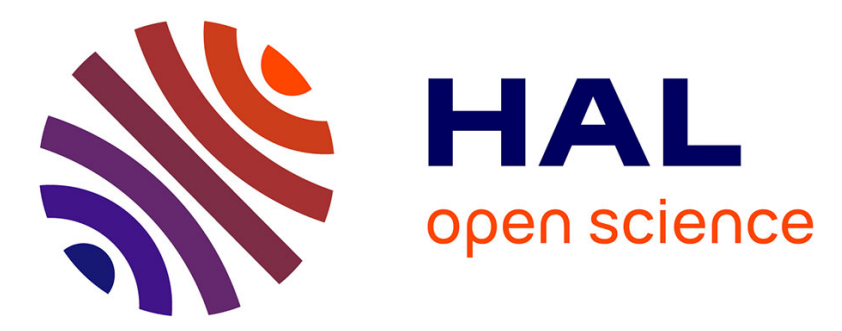

\title{
Functionalized TiO 2 Nanorods on a Microcantilever for the Detection of Organophosphorus Chemical Agents in Air
}

Urelle Biapo, Alessio Ghisolfi, Geoffrey Gerer, Denis Spitzer, Valérie Keller, Thomas Cottineau

\section{To cite this version:}

Urelle Biapo, Alessio Ghisolfi, Geoffrey Gerer, Denis Spitzer, Valérie Keller, et al.. Functionalized TiO 2 Nanorods on a Microcantilever for the Detection of Organophosphorus Chemical Agents in Air. ACS Applied Materials \& Interfaces, 2019, 11 (38), pp.35122-35131. 10.1021/acsami.9b11504 . hal-03093840

\section{HAL Id: hal-03093840 \\ https://hal.science/hal-03093840}

Submitted on 4 Jan 2021

HAL is a multi-disciplinary open access archive for the deposit and dissemination of scientific research documents, whether they are published or not. The documents may come from teaching and research institutions in France or abroad, or from public or private research centers.
L'archive ouverte pluridisciplinaire HAL, est destinée au dépôt et à la diffusion de documents scientifiques de niveau recherche, publiés ou non, émanant des établissements d'enseignement et de recherche français ou étrangers, des laboratoires publics ou privés. 


\title{
Functionalized $\mathrm{TiO}_{2}$ Nanorods on a Microcantilever for the Detection of Organophosphorus Chemical Agents in Air
}

\author{
Urelle Biapo, ${ }^{\dagger}$ Alessio Ghisolf, ${ }^{\dagger, \S}$ Geoffrey Gerer, ${ }^{\dagger \dagger}$ Denis Spitzer, ${ }^{\dagger}$ Valérie Keller, ${ }^{\dagger}$ (๑) \\ and Thomas Cottineau* ${ }^{* \dagger}$ (i)
}

\begin{abstract}
${ }^{\dagger}$ Institute of Chemistry and Processes for Energy Environment and Health (ICPEES), UMR 7515 CNRS-University of Strasbourg, 67087 Strasbourg, France

${ }^{\ddagger}$ French-German Research Institute of Saint-Louis, Nanomaterials for Systems under Extreme Stress (NS3E), UMR 3208 CNRS-University of Strasbourg, 68301 Saint-Louis, France

${ }^{\S}$ Department of Inorganic Chemistry and University Institute of Materials, University of Alicante, E-03080 Alicante, Spain

Supporting Information
\end{abstract}

\begin{abstract}
We report the fabrication of nanostructured microcantilevers employed as sensors for the detection of organophosphorus (OPs) vapors. These micromechanical sensors are prepared using a two-step procedure first optimized on a silicon wafer. $\mathrm{TiO}_{2}$ one-dimensional nanostructures are synthesized at a silicon surface by a solvothermal method and then grafted with bifunctional molecules having an oxime group known for its strong affinity with organophosphorus compounds. The loading of oxime molecules grafted on the different nanostructured surfaces was quantified by UV spectroscopy. It has been found that a wafer covered by vertically aligned rutile $\mathrm{TiO}_{2}$ nanorods (NRs), with an average length and width of $9.5 \mu \mathrm{m}$ and $14.7 \mathrm{~nm}$, respectively, provides an oxime function density of $360 \mathrm{nmol} \mathrm{cm}$. The optimized $\mathrm{TiO}_{2}$ nanorod synthesis was successfully reproduced on the cantilevers, leading to a homogeneous and reproducible $\mathrm{TiO}_{2} \mathrm{NR}$ film with the desired morphology. Thereafter, oxime molecules have been successfully grafted on the nanostructured cantilevers. Detection tests were performed in a dynamic mode by exposing the microcantilevers to dimethyl methylphosphonate (a model compound of toxic OPs agents) and following the shift of the resonant frequency. The nanostructure and the presence of the molecules on a $\mathrm{TiO}_{2} \mathrm{NR}$ surface both improve the response of the sensors. A detection limit of $2.25 \mathrm{ppm}$ can be reached with this type of sensor.
\end{abstract}

KEYWORDS: $\mathrm{TiO}_{2}$ nanostructures, micromechanical sensors, surface modification, hierarchical structures, organophosphorus detection

\section{INTRODUCTION}

Since the chemical attacks reported in Tokyo subway and Syria in the past few decades, ${ }^{1}$ the detection of organophosphorus compounds (OPs) became one of the major security issues to be solved in order to not only ensure civilian and military protection but also guarantee efficient decontamination after a terrorist attack or a technological disaster. These molecules, used not only as chemical warfare agents but also as pesticides, are highly toxic and considered as the most dangerous threats for animals and humans because they are effective at a very low concentration. ${ }^{2}$ These compounds belong to the nerve agent class that inhibits acetylcholinesterase, an enzyme responsible for the termination of the acetylcholine action at cholinergic synapses in the peripheral and central nervous system. ${ }^{2-4}$ In consequence, the interaction of OPs compounds on the nervous system would induce effects such as headache, excessive muscle contraction, convulsion, and respiratory failure that may result in death. ${ }^{4}$ The threshold level of exposition is usually referred as the immediately dangerous for life or health limit (IDLH), which corresponds to the concentration of a chemical in the air that would cause immediate or delayed permanent adverse health effects, after $30 \mathrm{~min}$ of unprotected exposure. This IDLH is $18.52 \mathrm{ppm}$ for malathion and $0.84 \mathrm{ppm}$ for parathion, two active organophosphorus molecules of commonly used pesticides. ${ }^{5}$ Whereas in the case of chemical warfare agents, the limits are about $0.03,0.008$, and $0.03 \mathrm{ppm}$ for sarin, soman, and tabun, respectively. ${ }^{6}$

Actually, none of the available OPs detection techniques completely satisfy all the needed safety requirements in terms of simultaneous high sensitivity, selectivity, portability, and fast response time at these IDLH limits. ${ }^{7}$ Such techniques are mainly based on well-established analytic chemistry techniques like ion mobility spectroscopy, mass spectrometry, gas chromatography, etc. ${ }^{6,8}$ These analyses are generally performed at centralized laboratories, requiring extensive human and analytical resources, thus limiting their applications under field conditions. ${ }^{9}$ An innovative and promising way to reduce the

Received: July 1, 2019

Accepted: August 30, 2019

Published: August 30, 2019 

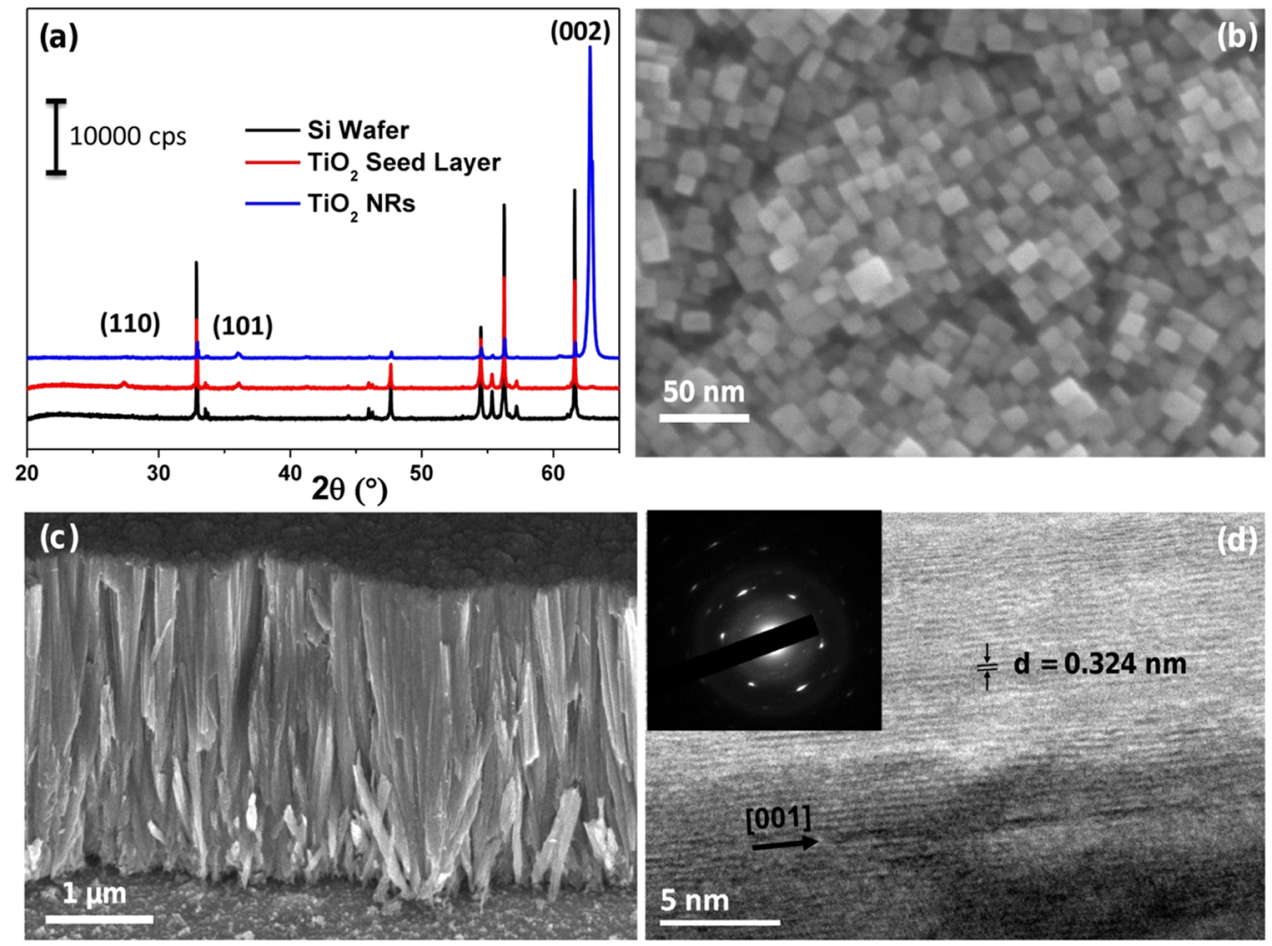

Figure 1. (a) $\mathrm{XRD}$ patterns of the as-prepared $\mathrm{TiO} 2 \mathrm{NR}$ film (blue), $\mathrm{TiO}_{2}$ seed layer made by sputtering (red), and a silicon wafer substrate as a reference (black). (b, c) SEM images of a vertically oriented rutile $\mathrm{TiO}_{2}$ nanorod film grown on a silicon wafer surface prepared in solvothermal conditions with $0.5 \mathrm{~mL}$ of TTIP, $15 \mathrm{~mL}$ of $\mathrm{HCl}, 15 \mathrm{~mL}$ of ETOH, $0.5 \mathrm{~mL}$ triethylamine hydrochloride (TEACl) at $150{ }^{\circ} \mathrm{C}$ for $8 \mathrm{~h},(\mathrm{~d}) \mathrm{TEM} \mathrm{image}$ of a single rutile $\mathrm{TiO}_{2}$ nanorod.

detection threshold is to use micromechanical sensors ${ }^{9-11}$ working in a dynamic mode, ${ }^{12}$ such as microcantilevers. Due to an actuation system, like a piezoelectric device usually employed for imaging in a typical AFM technique, the cantilever oscillates at its natural resonant frequency. The frequency shift can be measured using an appropriate readout system such as piezoresistive or optical detection systems. This resonance frequency is directly related to the spring constant and the mass of the beam. Any change in the mass of the cantilever, for instance, due to absorption of molecules, will result in a variation of the resonance frequency. This type of mass sensors is therefore suitable to identify and quantify a low amount of target molecules adsorbed on their surfaces. ${ }^{12,13}$

Although microcantilevers can be highly sensitive to a small variation in mass (i.e., $10^{-18} \mathrm{~g}$ ), this technique is still limited because they have a very small collection surface. This small surface should be increased in order to collect more molecules and then expect a higher level of sensitivity. Several ways are investigated to increase the microcantilever surface for improving the sensitivity, either by roughening or by coating a nanoporous film on the surface. ${ }^{12}$ The surface can be also activated with a selective layer or by functionalization with a specific molecule that can interact with the analyte. ${ }^{14-17}$ For instance, Pinnaduwage et al. functionalized a gold-coated cantilever with a self-assembled monolayer of 4-mercaptobenzoic acid in order to enhance the detection of two highly explosive compounds: PETN (pentaerythritol tetranitrate) and RDX (hexahydro-1,3,5-triazine). ${ }^{14}$ For the specific detection of trinitrotoluene (TNT) and its analogues in the gaseous phase, a nanoporous film containing tert-butylcalix[6] arene deposited on microcantilevers has demonstrated promising results. ${ }^{18}$ Other groups are focused on studying the interaction between OPs agents and metallic oxides such as $\mathrm{ZnO}, \mathrm{SiO}_{2}, \mathrm{ZrO}_{2}$, and
$\mathrm{TiO}_{2}$ for OPs detection or decontamination application with other methods. $^{1,19,20}$

Titanium dioxide $\left(\mathrm{TiO}_{2}\right)$ is a metal oxide used in several applications such as photocatalysis, photovoltaic, photoelectrochemistry, self-cleaning, gas detection, etc. ${ }^{21-23} \mathrm{TiO}_{2}$ naturally exists mainly in three crystalline polymorphs: anatase, rutile, and brookite. This material is highly stable in a wide range of $\mathrm{pH}$ even at the nanoscale. Furthermore, $\mathrm{TiO}_{2}$ is very interesting for applications where a large surface area is required because $\mathrm{TiO}_{2}$ can be made in various shapes, including nanotubes, nanorods, nanoparticles, or nanocubes, with a high aspect ratio. ${ }^{24}$ The only report on $\mathrm{TiO}_{2}$ nanostructures for application in the field of micromechanical sensors is based on $\mathrm{TiO}_{2}$ nanotubes synthesized through electrochemical anodization on microcantilever surfaces. The high surface achieved by such a nanostructured cantilever allowed us to improve the detection of TNT (trinitrotoluene) in the vapor phase to an estimated limit of $0.8 \mathrm{ppb} .^{12}$

Solution-based growth techniques, such as solvothermal methods, are also widely used to produce $\mathrm{TiO}_{2}$ onedimensional (1D) nanorods. ${ }^{25}$ These synthesis approaches offer many advantages for mass production of nanomaterials such as low cost and using a simple process; furthermore, wellcrystallized nanostructures can be obtained without the need of heat treatment. Compared to the electrochemical anodization method, which requires restrictive chemical precursors like fluoride and a thick titanium layer but also a conductive substrate in order to apply the high voltage required, the solvothermal methods can be achieved on different types of substrates and can be easily transferred in microelectronic fabrication. The growth of a $\mathrm{TiO}_{2} \mathrm{NR}$ film in solvothermal conditions was mainly done on FTO, ITO, or glass substrates. $^{26-31}$ Compared to the previous substrates, only 
few studies reported the use of a silicon substrate for hydrothermal $\mathrm{TiO}_{2}$ synthesis. $^{32-34}$ The growth of a $\mathrm{TiO}_{2}$ $\mathrm{NR}$ array at this kind of surface is limited by the difference between the crystal structures of the two materials, which could induce peeling of the oxide layer from the substrate. To overcome this issue, an initiation layer could be deposited on the silicon substrate. ${ }^{35}$

In this work, we describe the solvothermal synthesis of $\mathrm{TiO}_{2}$ nanorods and their functionalization, which have been first optimized on centimetric silicon wafer surfaces and then transferred to a microcantilever surface. This nanostructuration of silicon microcantilevers with $\mathrm{TiO}_{2}$ nanorods was performed in order to increase the surface of interaction with the analyte. Furthermore, to improve the selectivity toward OPs agents, the nanostructured cantilever surfaces were functionalized with specifically engineered organic molecules aimed to selectively and reversibly bind OPs compounds. Such nanostructured and functionalized cantilevers were then tested as OPs sensors in the vapor phase using dimethyl methylphosphonate (DMMP), well known as a safe simulant for nerve agents.

\section{RESULTS AND DISCUSSION}

A seed layer of metallic titanium $(c a .50 \mathrm{~nm})$ was initially coated on a silicon wafer surface in order to compensate the lattice mismatch between $\mathrm{TiO}_{2}$ and silicon. This layer was then annealed at $800{ }^{\circ} \mathrm{C}$ to oxidize the $\mathrm{Ti}$ surface in order to improve adherence and growth of $\mathrm{TiO}_{2} \mathrm{NRs}$ on the surface. Figure 1a shows X-ray diffraction (XRD) patterns of titaniumcoated silicon wafers before and after the solvothermal $\mathrm{TiO}_{2}$ nanostructuration. In the first case, we can notice that the pattern of the $\mathrm{TiO}_{2}$-assisted growth layer made via magnetron sputtering and annealing is in accordance with the tetragonal rutile crystalline phase of $\mathrm{TiO}_{2}$ (JCPDS file no. 21-1276). Only the two most intense diffraction peaks located at $27.5^{\circ}$ and $36.1^{\circ}((110)$ and $(101)$, respectively) of rutile are observed in this diffractogram, and their intensities are very weak. This is due to the low thickness of the oxide layer formed after the heat treatment of the titanium film.

$\mathrm{TiO}_{2}$ NRs were grown on the seed layer-coated silicon wafer surface through solvothermal method, typically in a mixture of ethanol and concentrated hydrochloric acid as a solvent and titanium tetraisopropoxide (TTIP) as a $\mathrm{TiO}_{2}$ precursor. After the solvothermal reaction, the white resulting film is only composed of rutile highly oriented along the $c$ axis. This was confirmed by the high intensity of the (002) rutile X-ray diffraction peak at $62.7^{\circ}$. The small full width at half-maximum $\left(0.296^{\circ}\right)$ of this peak suggests a good crystalline degree of the nanostructure. All the other diffraction peaks are attributed to silicon or small impurities on the X-ray source diffracting on the monocrystalline silicon substrate. Top and $45^{\circ}$ tilted crosssectional view scanning electron microscopy (SEM) images of the corresponding rutile $\mathrm{TiO}_{2}$ film are displayed in Figure $1 \mathrm{~b}, \mathrm{c}$, respectively. The as-synthesized film is composed of vertically aligned nanorods with top square facets, which grew perpendicular to the silicon surface. The average width of nanorods is approximately $15 \mathrm{~nm}$, and their length is about 4.2 $\mu \mathrm{m}$. Transmission electron microscopy (TEM) images of this sample were also collected, and the results obtained by selected-area electron diffraction (SAED) show the presence of some diffraction spots, which confirms the monocrystalline structure of the as-synthesized $\mathrm{TiO}_{2}$ nanorods. The average distance between two adjacent crystallographic plans measured using a TEM pattern at a high resolution is $0.324 \mathrm{~nm}$, which corresponds to the interplanar distance of the (110) crystallographic plane of rutile crystals. ${ }^{33}$ Furthermore, we could also confirm by TEM that the nanorods have a $[00 l]$ preferred growth direction as observed by $\mathrm{XRD}$ measurement for the abovementioned orientation of the $\mathrm{TiO}_{2}$ film.

This preferential orientation of the rutile crystals is due to the presence of chloride ions, which selectively hinder the growth of the (110) facet and promote the anisotropic growth of $\mathrm{TiO}_{2} 1 \mathrm{D}$ nanorods along the [00l] direction. This shapecontrol chemistry with hydrochloric acid has been already evidenced by other groups. ${ }^{36-38}$ Moreover, hydrochloric acid is also used in this synthesis to tailor the $\mathrm{pH}$ value of the growth solution and slow down the hydrolysis of titanium isopropoxide at a low temperature. This $\mathrm{TiO}_{2}$ precursor is highly sensitive to moisture and usually led to an amorphous phase of $\mathrm{TiO}_{2}$ when the hydrolysis is too fast.

In this study, various synthesis parameters were tuned to control the morphology, width, and length of the nanorods. The following parts will detail the effect of most influential parameters such as solvothermal temperature, nature of the synthesis solvent, and TTIP concentration. The objective was to further extend the surface area of $\mathrm{TiO}_{2}$ in order to improve oxime molecule loading and therefore sensor performances.

2.1. Effect of Synthesis Temperature. The reaction temperature during the solvothermal process can have an effect on the grain size and agglomeration among them. ${ }^{37}$ Figure 2

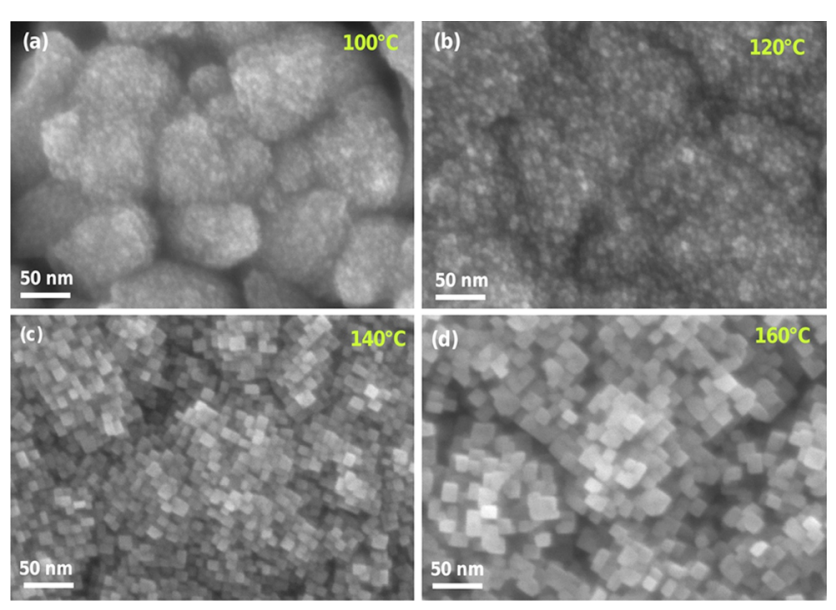

Figure 2. Top-surface SEM images of rutile $\mathrm{TiO}_{2}$ films grown at different synthesis temperatures: (a) $100{ }^{\circ} \mathrm{C}$, (b) $120^{\circ} \mathrm{C}$, (c) $140{ }^{\circ} \mathrm{C}$, and (d) $160{ }^{\circ} \mathrm{C}$ (keeping the other parameters constant).

displays top-surface SEM images of rutile films synthesized in $30 \mathrm{~mL}$ of an equal volume of hydrochloric acid and ethanol, $0.25 \mathrm{~mL}$ of TTIP, and $0.5 \mathrm{~mL}$ of triethylamine hydrochloride (TEACl) for $8 \mathrm{~h}$ but at different temperatures. From the top images and the side-view images (Figure S1), it is noticed that both nanorod diameter and length depend on the growth temperature. When the synthesis was performed at a low temperature $\left(100{ }^{\circ} \mathrm{C}\right)$, the $\mathrm{TiO}_{2}$ film was composed of bundles formed by the agglomeration of very small $\mathrm{TiO}_{2}$ nanorods (see Figure 2a). The agglomeration mainly occurs in nanomaterial synthesis with a small size in order to minimize the surface energy.

The diameter of the bundles of $\mathrm{TiO}_{2}$ nanorods is close to 85 $\mathrm{nm}$, and the thickness of the film is about $0.7 \mu \mathrm{m}$. When the temperature was raised to $120{ }^{\circ} \mathrm{C}$, the bundle is partially converted to discrete nanorods, and nanorod agglomeration 
was slightly reduced, as shown in Figure 2 b. Further increasing the growth temperature from 140 to $160{ }^{\circ} \mathrm{C}$ resulted in the formation of densely packed vertically oriented rutile nanorods with square facets on top (see Figure $2 \mathrm{c}, \mathrm{d}$ ). The nanorod lengths are $0.7,1.5,2.3$, and $2.7 \mu \mathrm{m}$ for the sample obtained at $100,120,140$, and $160{ }^{\circ} \mathrm{C}$, respectively. The width and the length increase with the reaction temperature, which indicates a change in the surface area for these samples.

In order to find the best type of nanostructuration for chemical functionalization, we grafted each type of the assynthesized nanorod surface with oxime molecules and estimated their loading abilities. Figure 3a shows the Raman
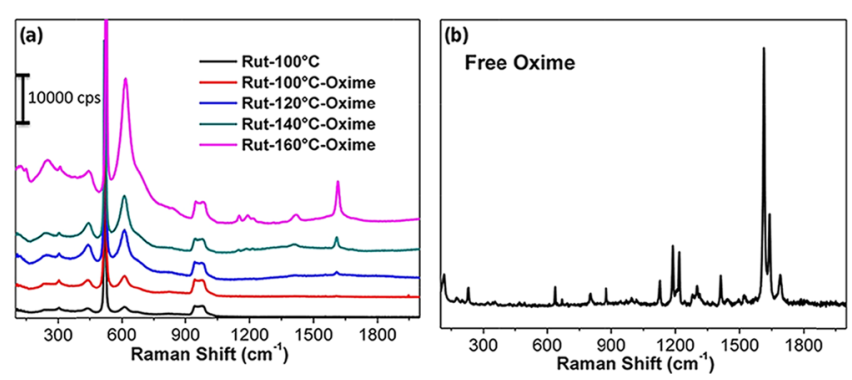

Figure 3. (a) Raman spectra of rutile nanorods synthesized at different growth temperatures and functionalized with oxime. (b) Raman spectra of free oxime molecules used for anchoring on each rutile $\mathrm{TiO}_{2}$ nanorod surface.

spectra of the nanorods synthesized at four different reaction temperatures $\left(100,120,140\right.$, and $\left.160{ }^{\circ} \mathrm{C}\right)$ and then functionalized with oxime molecules. The black spectrum in Figure $3 a$ represents the nongrafted sample, while others represent the grafted samples. All the spectra show Raman peaks at 443 and $609 \mathrm{~cm}^{-1}$ corresponding to $E_{\mathrm{g}}$ and $A_{1 \mathrm{~g}}$ active modes of the rutile $\mathrm{TiO}_{2}$ polymorph, respectively. ${ }^{38}$ These two predominant peaks are characteristics of rutile $\mathrm{TiO}_{2}$ single crystals. Another peak can be also seen at $230 \mathrm{~cm}^{-1}$; this peak $\left(E_{\mathrm{g}}\right)$ is assigned to multiple-phonon scattering of the secondorder-type, which is also a characteristic of the rutile $\mathrm{TiO}_{2}$ phase. This result agrees with that observed in the XRD analysis, where the presence of the rutile $\mathrm{TiO}_{2}$ phase has been already revealed (Figure S2). The intense narrow peak at 520 $\mathrm{cm}^{-1}$ and the large peak at $943 \mathrm{~cm}^{-1}$ arise from the silicon substrate. $^{39}$ In addition, for all the grafted samples, two supplementary peaks located at 1412 and $1610 \mathrm{~cm}^{-1}$ can be observed. Due to the large scale, these two peaks are not clearly visible on Figure 3a for a sample prepared at 100 and
$120{ }^{\circ} \mathrm{C}$; the corresponding spectra were then detailed in the Supporting Information (Figure S3). These peaks are typical vibration bands of the $\mathrm{COO}$ group and $\mathrm{C}=\mathrm{C}$ from the aromatic ring, ${ }^{40}$ thereby suggesting the presence of the oxime molecule onto the rutile $\mathrm{TiO}_{2}$ nanorod surface of each sample.

To check the presence of the molecules on the whole nanostructure, a fluorine-containing molecule (4-trifluoromethylbenzoic acid) was also grafted via a carboxylic site to the rutile nanorod surface prepared in ethanol at $150{ }^{\circ} \mathrm{C}$. We chose this molecule because it is easier to unambiguously distinguish fluorine compared to oxime, which consists mainly of oxygen, carbon, and nitrogen. Knowing that, the latter cited elements can be also adsorbed on different forms at the surface of bare $\mathrm{TiO}_{2}$ NRs. The fluorine modified nanostructure was analyzed by TEM equipped with an EDS analyzer, the chemical analysis confirm the presence of titanium and fluorine with approximately the same percentages from the top to the bottom of a nanorod surface (Figure S4).

A quantitative analysis was then performed by UV-vis spectroscopy titration. Oxime was desorbed by dipping each sample (prepared at different temperatures) in $3 \mathrm{~mL}$ of $0.01 \mathrm{M}$ $\mathrm{NaOH}$ for $30 \mathrm{~min}$. The obtained solution was then observed by UV-vis spectroscopy. An absorption band was observed for all the samples around $292 \mathrm{~nm}$ (see Figure 4b) corresponding to a typical aromatic $\pi-\pi^{*}$ transition and assigned to the phenyl molecule. These two characterizations both clearly demonstrate the anchoring of the oxime molecules on the $\mathrm{TiO}_{2}$ nanorod surface.

To determine the amount of grafted molecules at the $\mathrm{TiO}_{2}$ NR surface, a calibration curve was made by measuring the absorbance of oxime standard solutions (see Figure 4a). The maximum of the $\pi-\pi^{*}$ band around $292 \mathrm{~nm}$ was used for calibration. A simple linear regression (eq 1) was used to calculate the concentration of the grafted molecules on the rutile $\mathrm{TiO}_{2}$ surface by applying the Beer-Lambert law.

$$
A=17920 \times C
$$

where $C$ represents the concentration of the oxime in $\mathrm{M}$, and $A$ is the corresponding absorbance at $292 \mathrm{~nm}$. The slope of this linear model is in a good agreement with the value of the molar extinction coefficient of a typical $\pi-\pi^{*}$ transition. Knowing the oxime concentration and the volume of desorption solution for each sample, we can calculate the number of moles of oxime (n) per square centimeter of the wafer (knowing that the nanorods completely cover one side of the wafer surface).
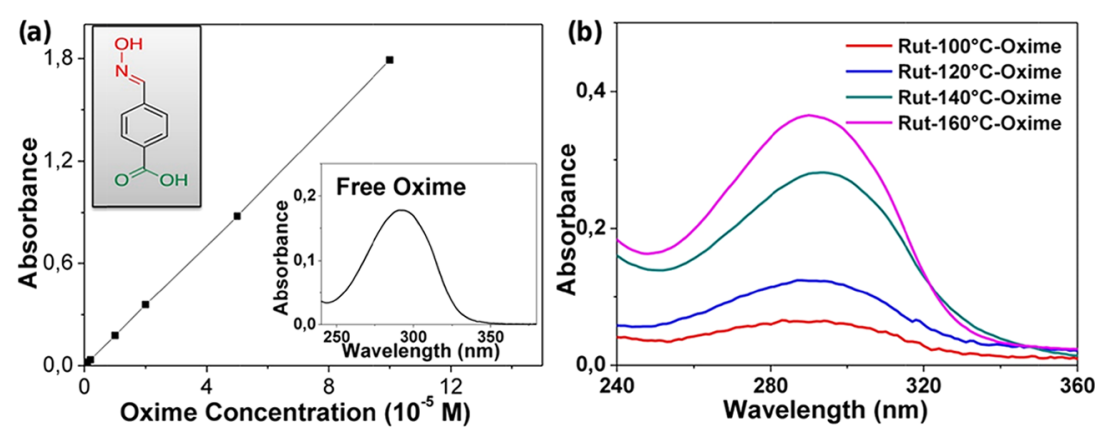

Figure 4. (a) UV-vis oxime calibration curve and UV-vis absorption spectrum of the free oxime molecule in $\mathrm{NaOH}$ solution ( $\mathrm{pH}$ 12). Inset shows the scheme of the oxime molecule (the green part is the tethering site for the $\mathrm{TiO}_{2}$ nanostructure, and the red one is the oxime function). (b) UV-vis spectra of desorbed oxime anchored on each rutile $\mathrm{TiO}_{2}$ nanorod surface. 
Table 1 shows the oxime loading on $\mathrm{TiO}_{2}$ NRs obtained at different reaction temperatures. As listed in Table 1 , it can be

Table 1. $\mathrm{TiO}_{2}$ Nanorod Morphologies and Oxime Molecules Loading Obtained at Different Reaction Temperatures

$\begin{array}{clccc}\begin{array}{c}\text { temperature } \\ \left({ }^{\circ} \mathrm{C}\right)\end{array} & \begin{array}{c}\text { small width } \\ (\mathrm{nm})\end{array} & \begin{array}{c}\text { large width } \\ (\mathrm{nm})\end{array} & \text { length }(\mu \mathrm{m}) & \begin{array}{c}n_{\text {oxime }} \\ \left(\mathrm{nmol} \mathrm{cm}^{-2}\right)\end{array} \\ 100 & <7 & & 0.7 \pm 0.07 & 11 \pm 4 \\ 120 & <7 & & 1.5 \pm 0.13 & 25 \pm 4 \\ 140 & 7.0 \pm 0.9 & 9.0 \pm 1.2 & 2.3 \pm 0.08 & 47 \pm 4 \\ 150 & 10.2 \pm 1 & 12.0 \pm 1.9 & 2.5 \pm 0.04 & 70 \pm 4 \\ 160 & 11.3 \pm 1.4 & 15.5 \pm 2.3 & 2.7 \pm 0.06 & 61 \pm 4\end{array}$

seen that the amount of molecules increase with the temperature from 11 to $70 \mathrm{nmol} \mathrm{cm} \mathrm{cm}^{-2}$ for nanorods synthesized at 100 and $150{ }^{\circ} \mathrm{C}$, respectively. This can be due to augmentation of the $\mathrm{TiO}_{2}$ nanorod length and the formation of free spaces between adjacent nanorods when the bundles of nanorods disappeared. However, a slight decrease in the amount of molecules is exhibited at $160{ }^{\circ} \mathrm{C}$. This decrease is probably due to the larger width of rutile $\mathrm{TiO}_{2}$ NRs obtained at this temperature, which could significantly influence the density of nanorods at the silicon surface and therefore reduce the surface area of the film. In order to explain this change in the grafting density, we tried to calculate the surface offered by the $\mathrm{TiO}_{2}$ nanostructure using the SEM image. Considering that the nanorods have a rectangular shape and the entire surface is available for molecule adsorption, a single nanorod surface is calculated according to eq 2 :

$$
S_{\mathrm{NR}}=w W+2 w L+2 w L
$$

where $w$ and $W$ are the small and large widths of the nanorods, respectively, and $L$ is the length of the rods. This surface $\left(S_{\mathrm{NR}}\right)$ should then be multiplied by the density of the nanorods on the silicon wafer to obtain the nanostructure surface. As observed on all SEM images, nanorods are densely packed at the surface of the silicon, and the evaluation of their density from SEM images is difficult due to contrast issue and screening effect from longer nanorods. To evaluate the density of nanorods, we compared the surface area determined experimentally by BET measurement $\left(S_{\text {exp }}\right)$ for a reference sample with its theoretical surface area $\left(S_{\text {th }}\right)$ calculated taking into account the maximal density of nanorods derived from the square section of one nanorod (eq 3). The surface area of this reference $\mathrm{TiO}_{2} \mathrm{NR}$ film coating one side of a $14.7 \mathrm{~cm}^{2}$ wafer was determined by $\mathrm{Kr}$ gas adsorption. The BrunauerEmmett-Teller (BET) surface area measured was $1.496 \pm$ $0.017 \mathrm{~m}^{2}$, corresponding to an average experimental surface $S_{\text {exp }}$ of $1018 \mathrm{~cm}^{2}$ for $1 \mathrm{~cm}^{2}$ of wafer. The geometrical parameters of the $\mathrm{TiO}_{2} \mathrm{NRs}$ of this film are $3 \mu \mathrm{m}$ for the length and 9.5 and $12.2 \mathrm{~nm}$ for the small and large widths, respectively. The maximum theoretical density $\left(N_{\mathrm{th}}\right)$ of nanorods is consequently $8.63 \times 10^{11} \mathrm{~cm}^{-2}$, and the theoretical surface $S_{\text {th }}$ of the nanostructure given by eq 3 is then $1123 \mathrm{~cm}^{2}$ per square centimeter of wafer.

$$
S_{\text {th }}=S_{\mathrm{NR}} \times N_{\text {th }}
$$

The ratio between the measured BET surface $\left(S_{\text {exp }}\right)$ and the calculated surface from SEM $\left(S_{\text {th }}\right)$ is 0.906 . Since the NRs are well crystallized and no roughness arises from the side of the NRs as demonstrated by TEM images, this value gives an idea about the compactness of the nanorod film. This coefficient should then be taken into account while estimating the surface from the SEM image. Based on this knowledge, the nanostructures synthesized at 150 and $160{ }^{\circ} \mathrm{C}$ have an estimated surface of 820 and $750 \mathrm{~cm}^{2}$, respectively, for $1 \mathrm{~cm}^{2}$ of wafer; this result clearly confirms that the slight reduction in the amount of grafted molecules is related to the diminution of the surface area for the sample prepared at a high temperature.

2.2. Effect of Solvothermal Synthesis Solvent. In order to achieve other nanoarchitectures and possibly improve the oxime grafting density onto the rutile surface, ethanol was replaced with ethylene glycol (EG) or water during the solvothermal synthesis while keeping the other parameters constant. From the SEM images of these samples (Figure $5 \mathrm{a}, \mathrm{b})$, it can be found that the morphology of the rutile $\mathrm{TiO}_{2}$
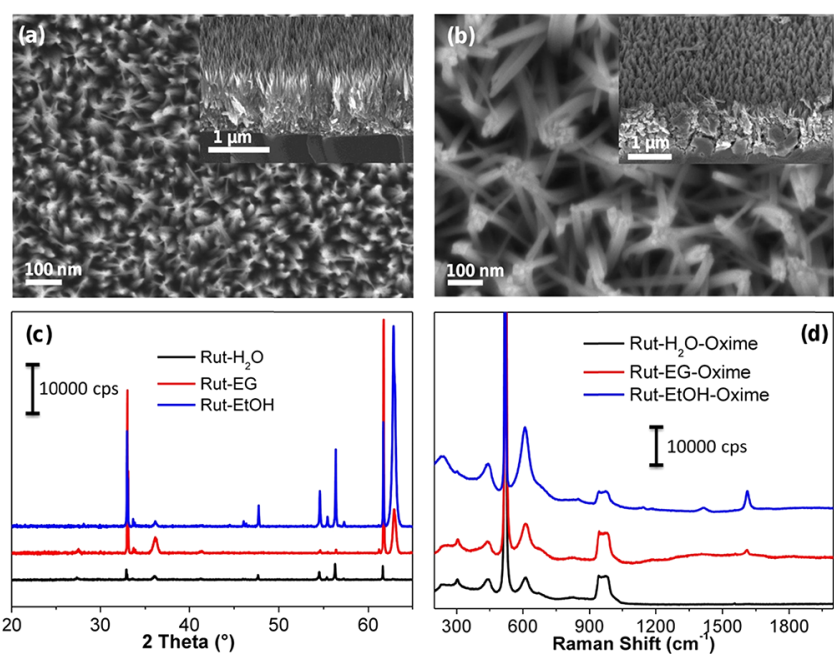

Figure 5. Top and cross-sectional (inset) SEM images of rutile $\mathrm{TiO}_{2}$ NRs prepared by replacing ethanol with (a) ethylene glycol and (b) water in the presence of hydrochloric acid and $0.25 \mathrm{~mL}$ of TTIP at $150{ }^{\circ} \mathrm{C}$ for $8 \mathrm{~h}$. (c) XRD of the nanostructure prepared with water, ethylene glycol, and ethanol. (d) Raman spectra of the three different nanostructures functionalized with oxime molecules.

phase obtained with water and ethylene glycol differs significantly from the one prepared in ethanol medium. In the case of ethylene glycol, well-separated vertically oriented needle-like structures with a diameter of $13.5 \mathrm{~nm}$ were obtained instead of the $\mathrm{TiO}_{2} \mathrm{NRs}$ with square facets given by ethanol (see Figure 5a).

In the case of water used as a solvent, randomly oriented nanorods involving a low density of nanorods at the silicon surface were obtained (Figure $5 \mathrm{~b}$ ). The vertical orientation observed with the needle-like structure indicates a preferred growth direction of rutile crystals as in the case of those obtained in ethanol. Nevertheless, XRD analysis of the samples clearly indicates that this orientation is less pronounced as in the case of ethanol (Figure 5c). The intensity of the (002) diffraction peak is strongly reduced, while the (101) signal is more intense for the sample prepared with ethylene glycol when compared to the nanostructure prepared in ethanol. In the case of water used as a solvent, the (002) peak is absent, and only two small rutile peaks, (110) and (101), can be seen in Figure 5c. Since the needle-shaped nanostructure obtained using ethylene glycol seem less densely packed with more accessible porosity, they may be beneficial to reach a higher oxime grafting density and also a better accessibility for the targeted molecules during the detection. The number of 
adsorbed molecules could therefore be increased with this nanostructure as well. However, for the sample synthesized in the presence of water, the coalescence between neighboring nanorods should result in a reduced accessible surface area.

We functionalized these new nanostructures (obtained in water and ethylene glycol) with oxime, in the conditions described in Section 4, to evaluate the accessible surface area achieved with these nanostructures. From the Raman spectra shown in Figure 5d, the two peaks located at 1412 and 1610 $\mathrm{cm}^{-1}$ related to the molecule are observed for the nanostructure obtained from ethylene glycol, while they are not observed for water. In this latter case, the quantity of the molecules anchored to the surface is certainly very low and below the Raman detection threshold. Concerning the UV-vis titration, oxime loading was 8 and $34 \mathrm{nmol} \mathrm{cm}{ }^{-2}$ for water and ethylene glycol nanostructures, respectively. These results confirmed that the agglomeration of nanorods when water is used as the solvent reduces the available surface, while the better separation of the needles obtained in the case of ethylene glycol improves the grafting. Nevertheless, the needlelike structure only allows half of the grafting density than the more densely packed square facet nanorods $\left(70 \mathrm{nmol} \mathrm{cm}{ }^{-2}\right)$ obtained with ethanol that seems to remain the best candidate for our purpose regarding the density of sensing sites.

2.3. Effect of TTIP Volume. It is known that the nucleation and the growth rate of $\mathrm{TiO}_{2}$ NRs are closely related to the $\mathrm{TiO}_{2}$ precursor concentration in the growth solution. $^{25,35}$ Figure 6 displays the typical SEM images (top;
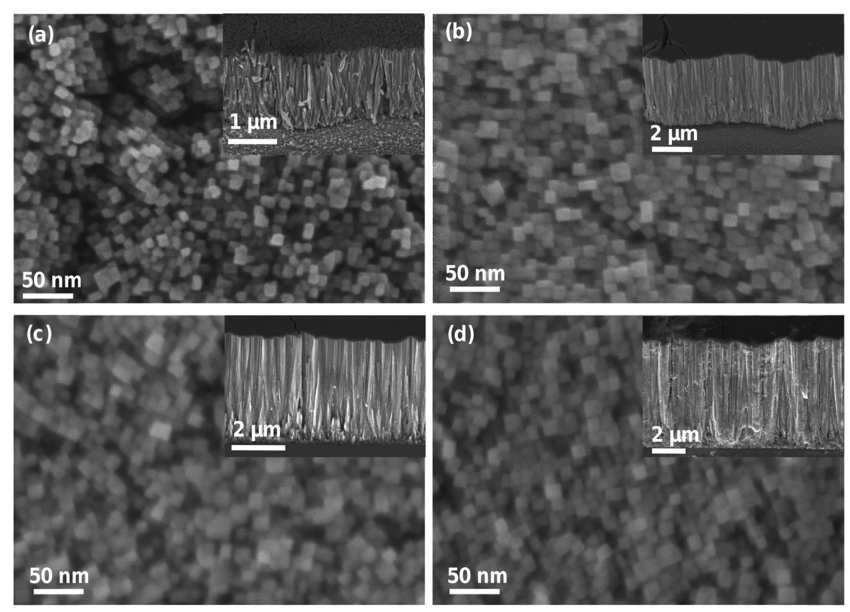

Figure 6. Top- and side-view SEM images (in inset) of rutile $\mathrm{TiO}_{2}$ NR films grown at $150{ }^{\circ} \mathrm{C}$ for $8 \mathrm{~h}$ with different volumes of TTIP in a mixture (1:1) of hydrochloric acid and ethanol: (a) $0.25 \mathrm{~mL}$, (b) 1 $\mathrm{mL},(\mathrm{c}) 2 \mathrm{~mL}$, and (d) $3 \mathrm{~mL}$.

cross-sectional view in the inset) of nanorods prepared at 150 ${ }^{\circ} \mathrm{C}$ for $8 \mathrm{~h}$ in $15 \mathrm{~mL}$ of ethanol, $15 \mathrm{~mL}$ of hydrochloric acid, 0.5 $\mathrm{mL}$ of triethylamine hydrochloride, and different TTIP volumes ranging from 0.25 to $3 \mathrm{~mL}$. From the SEM images, it can be observed that the samples exhibit a uniform layer of vertically aligned square facet rutile $\mathrm{TiO}_{2}$ nanorods whatever the TTIP volume in the solution. Several groups reported that, when the precursor volume is low, nanorods did not grow orthogonally to the substrate but tilted because the nucleation density is too low, and the probability for a nanorod of colliding with its neighbors decreases. ${ }^{29,30}$ Interestingly, in this study, such behavior is not observed, since the nanorods grow perpendicular to the silicon wafer for all amounts of TTIP tested. This might be due to the high crystallinity of the initial $\mathrm{TiO}_{2}$ thin film deposited via sputtering that allows a uniform and dense distribution of the seeds of $\mathrm{TiO}_{2}$ NRs. The rutile $\mathrm{TiO}_{2}$ grains, which compose this layer, are already oriented and could directly improve the epitaxial growth and the orientation of rutile nanorods film (see the XRD pattern in Figure 1) during the solvothermal process.

From Figure $7 b$, we can notice that the average length of nanorods is gradually increased with respect to the TTIP

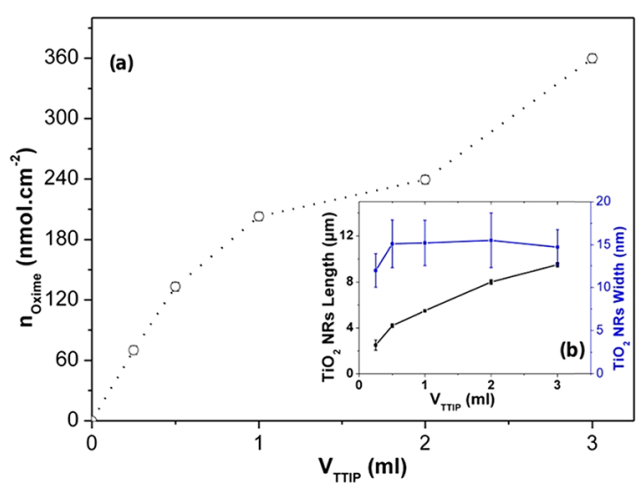

Figure 7. (a) Oxime loading onto $\mathrm{TiO}_{2}$ nanorods synthesized at different TTIP volumes. (b) Influence of the TTIP volume on the length and the diameter of the nanorods.

volume, whereas their diameter does not significantly change at a high TTIP volume. This clearly demonstrates that the axial growth of nanorods is more favored than the lateral one while increasing the precursor amount. We can also observe that the amount of grafted oxime molecules increased significantly together with the length of nanorods, suggesting that all the side of the nanorods are accessible for grafting despite the high compactness of the film. Almost $360 \mathrm{nmol} \mathrm{cm} \mathrm{cm}^{-2}$ of oxime could be attached to nanorods having a length of $9.5 \mu \mathrm{m}$, as displayed in Figure 7a. Increasing the length of nanorods with top square facets (EtOH case) seems to be the best way to enhance the molecule loading on a rutile $\mathrm{TiO}_{2} 1 \mathrm{D}$ film.

From this parametric study, it appears that it is better to use ethanol as the solvent and a moderate growth temperature to prepare highly ordered $\mathrm{TiO}_{2}$ nanorods arrays on the silicon surface. We found that changing the amount of titanium precursor allows an easy control on their length in order to achieve a high loading of grafted molecules.

2.4. Cantilever Surface Modifications and Detection Tests. Since $\mathrm{TiO}_{2}$ synthesis in ethanol gives the nanostructure with the higher adsorption capacity, we applied this optimized synthesis for cantilever nanostructuration. As described above on the silicon substrate, a seed layer of titanium was coated on one side of the cantilever surface before the solvothermal synthesis. The other side of the cantilever (typically the upper surface) was kept uncoated for laser beam reflection. The nanostructure growth was performed with $0.5 \mathrm{~mL}$ of TTIP at $150{ }^{\circ} \mathrm{C}$ for $8 \mathrm{~h}$. From the SEM image of this sample depicted in Figure 8, we can see that a homogeneous layer of the $\mathrm{TiO}_{2}$ nanostructure completely covers the surface of the microcantilever. The SEM image recorded at a high magnification showed that the morphology of $\mathrm{TiO}_{2}$ obtained at the micrometric surface of the cantilever is very similar to the $\mathrm{TiO}_{2}$ nanostructure synthesized on silicon wafers $\left(1 \times 1 \mathrm{~cm}^{2}\right)$. The growth of the similar nanostructure on both types of support (i.e., silicon wafer and microcantilever) highlighted the 

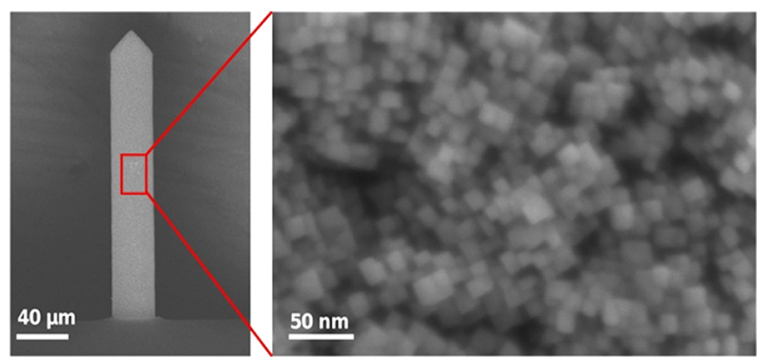

Figure 8. $\mathrm{TiO}_{2}$ nanostructured cantilever prepared in ethanol, hydrochloric acid, $0.5 \mathrm{~mL}$ of TEACl, and $0.5 \mathrm{~mL}$ of TTIP at 150 ${ }^{\circ} \mathrm{C}$ for $8 \mathrm{~h}$.

reproducibility and the versatility of this optimized $\mathrm{TiO}_{2} \mathrm{NR}$ synthesis even when downsizing the substrate by 2 orders of magnitude.

These modified cantilevers were then tested as OPs micromechanical sensors. The detection tests of DMMP were first done with the microcantilevers modified with the different nanostructures obtained in the three different solvents (ethanol, water, and ethylene glycol). The adsorption measurements of DMMP on these samples are illustrated in Figure 9a. As observed for the synthesis with ethanol, the nanostructure achieved on microcantilevers with water and ethylene glycol are highly similar to $\mathrm{TiO}_{2}$ nanostructured wafers synthesized with the same solvents (Figure S5). The three cantilevers nanostructured in the different solvents showed a resonance frequency drop when DMMP vapors were generated near their surfaces within a few seconds. This result indicates the adsorption of DMMP on the cantilever surfaces and, consequently, the detection of the target molecule. The frequency shifts correspond to $11,256,556$, and $833 \mathrm{~Hz}$ for uncoated microcantilever and the ones nanostructured in ethylene glycol, water, and ethanol, respectively. When the air containing the DMMP vapor is replaced after $10 \mathrm{~min}$ by the reference air flux, the DMMP molecules are desorbed from the nanostructured cantilevers, and the resonance frequency returns to its baseline value after a short period. The higher frequency shift obtained with the cantilever nanostructured in ethanol $(\approx 75$ times the value of pristine silicone lever) confirms that a large part of its surface area is accessible for the analyte even though the film appears highly dense. The active surface measured by krypton adsorption $\mathrm{BET}$ is $188 \mathrm{~m}^{2} / \mathrm{g}$. The lower response from the cantilever synthesized in EG compared to the one synthesized water was not expected since the oxime loading on the wafer surface was more important for the EG nanostructure, suggesting a higher available surface area. At room temperature, the adsorption mechanism of $\mathrm{DMMP}$ on $\mathrm{TiO}_{2}$ involves the hydrogen bonds between the $\mathrm{P}=\mathrm{O}$ function and the surface hydroxyl groups of the oxide. ${ }^{41}$ Ethylene glycol has a coordination ability with transition metal ions, ${ }^{29,42}$ and it can form glycolate complexes with $\mathrm{Ti}(\mathrm{IV})$ ions during the synthesis of $\mathrm{TiO}_{2}$. Since there is no heat treatment after the solvothermal synthesis, some glycolate molecules can remain in the crystal structure and might therefore reduce the possibility of this nanostructure to form hydrogen bonds with DMMP, resulting in a lower sensor activity.

We have also shown on wafer surfaces that increasing the length of nanorods by increasing the TTIP volume during the solvothermal process resulted in a higher amount of grafted molecules. The cantilevers nanostructured in a high TTIP volume (from 1 to $3 \mathrm{~mL}$ ) exhibited significant instability during the detection measurements. It was difficult to track the resonance frequency of these cantilevers having longer nanorods over the whole experiment duration. Some of them scatter the laser beam and led to its drift onto the photodiode. For this reason, the tests were limited to cantilevers nanostructured in a low TTIP volume $(0.25$ and $0.5 \mathrm{~mL})$, which lead to the shorter nanorods. The results obtained concerning the DMMP adsorption support the previous
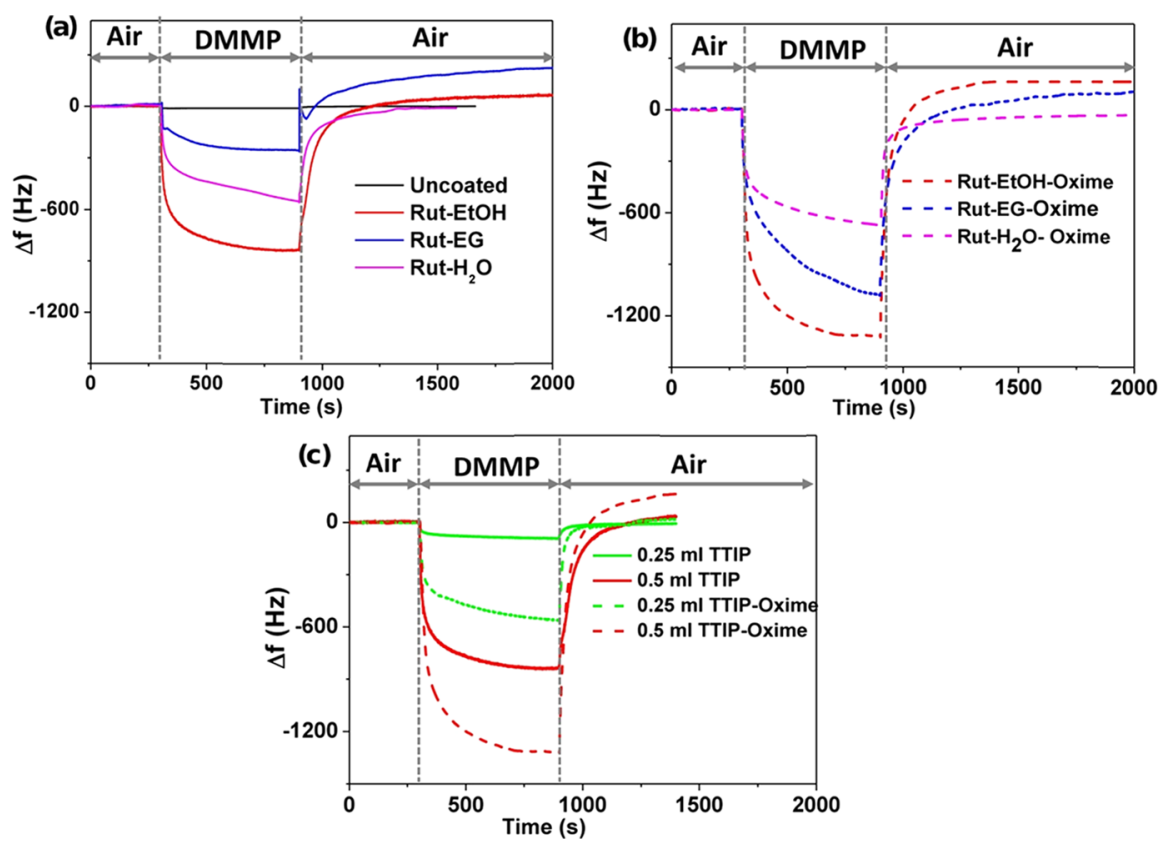

Figure 9. Measured resonnant frequency responses for exposition to $500 \mathrm{ppm}$ of DMMP vapor for (a) cantilevers prepared in $0.5 \mathrm{~mL}$ of TTIP and a solvent (ethanol, ethylene glycol, or water) and pristine microcantilever and (b) oxime-functionalized cantilevers. (c) Cantilevers prepared in 0.25 and $0.5 \mathrm{~mL}$ of TTIP. 
assumption that the frequency drop is low for the shorter nanorods and higher for the longer one (Figure 9c).

The nanostructured cantilevers were then functionalized with oxime molecules with the same procedure used for nanostructured wafers. In this case, no quantitative or qualitative analysis of the grafted molecules was possible because of the very small size of the substrate, but since the nanostructures are similar to the ones obtained on the wafers, we assume that the oxime loading is similar. The frequency shifts of the cantilevers nanostructured in 0.25 and $0.5 \mathrm{~mL}$ of TTIP have significantly increased when oxime molecules are attached to their surfaces. A similar behavior was found for the nanostructures prepared in ethanol and ethylene glycol, and the presence of oxime molecules improves the sensing performances of the cantilevers as well (see Figure 9b). However, no obvious change was observed between the cantilever nanostructured in water and the same cantilever functionalized with oxime. This result can be understood by the low amount of bound oxime molecules at the surface of the nanostructure synthesized in water, as shown at a frequency shift of $1319 \mathrm{~Hz}$ in accordance with the high surface area and the high loading of grafting offered by the nanostructure. These tests were reproduced several times for each sample and show good reproducibility of the response (see example in Supporting Information, Figure S6).

According to these preliminary results, we demonstrate that the functionalization of the nanorods with oxime molecules enhances the response of the cantilevers toward DMMP molecules. The resonance frequency of the microcantilever before the adsorption of DMMP was $f_{0}=172.42 \mathrm{kHz}$, with a noise corresponding to $\pm 2 \mathrm{~Hz}$. Considering that a detectable signal is equal to three times the noise, the smallest detectable frequency drop is $6 \mathrm{~Hz}$. An estimation of the detection limit can be determined using this value of resonance frequency $\left(f_{\Delta m}=f_{0}-6\right)$ and the following equation:

$$
\Delta m=m_{\mathrm{b}}\left(\frac{f_{0}^{2}}{f_{\Delta m}^{2}}-1\right)
$$

$\Delta m$ represents the adsorption mass of the DMMP, and $m_{\mathrm{b}}$ is the mass of the silicon microcantilever coated with $\mathrm{TiO}_{2}$ nanorods and functionalized with oxime calculated considering the mass of the $\mathrm{Si}$ beam and the mass of $\mathrm{TiO}_{2}$ covering one side (see calculus details in the Supporting Information). This results in a theoretical detection limit of $2.25 \mathrm{ppm}$ of DMMP with this functionalized and nanostructured sensor. Even though this concentration is still high compared to the IDLH limit of the OPs, this result provides a kind of guideline for developing new nanostructures with higher sensitivity. A table showing the performance of some micromechanical OPs sensors is presented in the Supporting Information for comparison.

We are currently investigating the DMMP adsorption measurements at a low concentration with and without interfering gases in the laboratory before conducting some tests on real OPs. In order to improve the detection limit, different ways will be explored such as a better control of the resonant frequency tracking that should improve the signal-tonoise ratio and should allow working with longer nanorods that could provide a higher surface area.

\section{CONCLUSIONS}

In summary, we achieved the solvothermal synthesis of $\mathrm{TiO}_{2}$ nanostructures on the silicon surface and their functionalization with oxime molecules. This molecule has been chosen because it could have a specific affinity with organophosphorus compounds. We demonstrate that the nanostructuration of $\mathrm{TiO}_{2}$ can be efficiently transferred from the centimetric surface of silicon wafers to the micrometric surface of cantilevers with a good reproducibility and the suitable morphology. Our results highlighted the versatility of the growth process of $\mathrm{TiO}_{2}$ nanostructures at the surfaces of wafers and cantilevers in solvothermal conditions. Different aspects of the nanostructure preparation, relevant for sensing performances such as the morphology and size of $\mathrm{TiO}_{2}$ nanorods can be well controlled by adjusting different synthesis parameters such as the nature of the solvent and TTIP volume. The amount of grafted molecules is strongly affected by the active surface of nanorods, and this surface has a significant impact on the microcantilevers response. The surface enhancement obtained by the nanostructuration increases the frequency shift signal by 75 times. Furthermore, the presence of the oxime-terminated molecules grafted at the surface allows us also to double the sensitivity toward OPs compounds in the gas phase. This result could probably pave the way for designing new highly responsive sensors having high molecular recognition with not only organophosphorus compounds but also other compounds by changing the nature of the grafted molecule. Our work will now aim at improving the DMMP vapor generation system to reach lower concentrations and improve the resonant frequency acquisition to lower the noise of our system.

\section{EXPERIMENTAL SECTION}

4.1. Materials. Titanium tetraisopropoxide (TTIP; $\geq 97 \%$ ) and triethylamine hydrochloride (TEACl; 98\%) were purchased from Sigma-Aldrich and used as received. Hydrochloric acid (37\%; Fisher Scientific), ethanol, acetonitrile, and tert-butanol were also used without any purification. Silicon wafers ( $\mathrm{Si}, \mathrm{p}$-type [100]; one side polished) were bought from Siegert Consulting e.K. Tipless silicon microcantilevers (TL-NCL-50 type) having $7 \mu \mathrm{m}$ in thickness, 225 $\mu \mathrm{m}$ in length, $38 \mu \mathrm{m}$ in width, and a nominal resonant frequency range of $146-236 \mathrm{kHz}$ were purchased from NanoSensors.

4.2. $\mathrm{TiO}_{2}$ Seed Layer Deposition. The substrates were first cleaned by a three successive ultrasonic baths in acetone, ethanol, and water for $15 \mathrm{~min}$ each and then dried under nitrogen flow at room temperature. Then, a layer of ca. $50 \mathrm{~nm}$ of titanium was deposited on the cleaned wafer surfaces via DC magnetron sputtering using argon as a carrier gas for titanium deposition (argon pressure, $2 \times 10^{-2}$ mbar). The plasma was excited by applying a DC power density of $1.37 \mathrm{~W} \mathrm{~cm}^{-2}$ with the initial vacuum set to $10^{-5}$ mbar. After the deposition, the titanium layer was annealed under air flow at $800{ }^{\circ} \mathrm{C}$ for $6 \mathrm{~h}$ (ramp of $10^{\circ} \mathrm{C} / \mathrm{min}$ ) to form a crystallized oxide layer.

4.3. $\mathrm{TiO}_{2}$ Nanorod Synthesis on $W$ afer. $\mathrm{TiO}_{2} \mathrm{NRs}$ were grown on the seed layer-coated silicon wafer surface through a solvothermal method. Typically, $15 \mathrm{~mL}$ of hydrochloric acid and $15 \mathrm{~mL}$ of ethanol were mixed and magnetically stirred for $5 \mathrm{~min}$. Then, $0.25 \mathrm{~mL}$ of TTIP and $0.5 \mathrm{~mL}$ of ethanol saturated with triethylamine hydrochloride salt were added to the mixture. The obtained transparent solution was stirred for another $5 \mathrm{~min}$ and then transferred in a 100 $\mathrm{mL}$ Teflon-lined stainless autoclave. A piece of $1 \times 1 \mathrm{~cm}^{2}$ of the Ticoated wafer was attached to a sample holder so that the substrate was completely immersed in the precursor solution with the coated side kept facing down during the synthesis. The reaction was carried out at $150{ }^{\circ} \mathrm{C}$ for $8 \mathrm{~h}$. After the synthesis, the film deposited on the substrate was rinsed with ethanol and distilled water and finally dried with nitrogen flux. 
4.4. Nanostructured Surface Chemical Functionalization. The $\mathrm{TiO}_{2}$ resulting nanomaterials were functionalized with (E)-4((hydroxyimino)methyl)benzoic acid, a bifunctional oxime containing a carboxyl group as tethering function for the $\mathrm{TiO}_{2}$ nanostructured surface (Figure 4). This molecule was prepared as described in the literature. ${ }^{43}$ Concerning the grafting conditions, the oxime $(0.010 \mathrm{~g})$ was dissolved in $5 \mathrm{~mL}$ of a mixture acetonitrile/tert-butanol (1:1). A $\mathrm{TiO}_{2}$ nanorod-coated wafer was then dipped in this solution and heated at $70^{\circ} \mathrm{C}$ for $24 \mathrm{~h}$. The samples were then rinsed with acetone and ethanol in order to remove any residual oxime molecules, which are not covalently attached to the $\mathrm{TiO}_{2} \mathrm{NR}$ surface. After optimization on the $\mathrm{Si}$ wafer, the $\mathrm{TiO}_{2} \mathrm{NR}$ synthesis and chemical functionalization were then adapted and applied to microcantilevers.

4.5. Characterization. XRD spectra were recorded in a Bruker D8 diffractometer with $\mathrm{Cu} \mathrm{K} \alpha$ radiation $(\lambda=1.5418 \AA)$ from $20^{\circ}$ to $65^{\circ}$. SEM was performed with a JEOL JSM-6700F FEG microscope, and TEM was performed with a JEOL 2100F TEM/STEM microscope. The Raman spectra of the samples were recorded in the spectral range of $50-3000 \mathrm{~cm}^{-1}$ using a Raman spectrometer (LabRAMAN Aramis Instrument) laser with an excitation wavelength of $532 \mathrm{~nm}$. UV-vis spectroscopy was done with a PerkinElmer Lambda 950 spectrometer in the region of $200-400 \mathrm{~nm}$. The surface area of the nanostructure was measured at $77 \mathrm{~K}$ using krypton adsorption analysis on a Micromeritics ASAP 2020 surface analyzer. Before the measurement, the sample was outgassed at $300{ }^{\circ} \mathrm{C}$ for $2 \mathrm{~h}$.

4.6. Sensing Measurements. A stream of air $\left(50 \mathrm{~mL} \mathrm{~min}{ }^{-1}\right)$ controlled by a mass flowmeter was flowed through a saturator containing DMMP in the liquid phase. Afterward, this flow loaded with $500 \mathrm{ppm}$ of DMMP vapor was sent to the detection chamber where the microcantilever is loaded in the head of a PicoSPM AFM multimode microscope to record the resonance frequency. All measurements were done at this concentration and at a stable room temperature $\left(23^{\circ} \mathrm{C}\right)$. A two-way valve was used to switch between reference air and air containing DMMP gas flow. During the test, the cantilever was first kept upon air flow until its resonance frequency is stabilized, before switching to the air/DMMP way. After $10 \mathrm{~min}$ of continuous DMMP exposition, the air/DMMP mixture was replaced by the reference air.

\section{ASSOCIATED CONTENT}

\section{S Supporting Information}

The Supporting Information is available free of charge on the ACS Publications website at DOI: 10.1021/acsami.9b11504.

Side-view SEM images and XRD patterns of rutile $\mathrm{TiO}_{2}$ films grown at different synthesis temperatures, Raman spectra of rutile $\mathrm{TiO}_{2}$ films grown at 100 and $120^{\circ} \mathrm{C}$ and functionalized with the oxime molecule, TEM image of nanorods functionalized with the fluorine molecule, mass percentages of fluorine and titanium on the nanorod surface, SEM image of $\mathrm{TiO}_{2}$ nanostructured cantilever surfaces prepared in different solvents, cycle detection measurement of nanostructured and functionalized cantilever, detailed calculus of sensor detection limit, and comparison of different OPs micromechanical sensors (PDF)

\section{AUTHOR INFORMATION}

\section{Corresponding Author}

*E-mail: cottineau@unistra.fr.

\section{ORCID $\odot$}

Valérie Keller: 0000-0002-3381-1446

Thomas Cottineau: 0000-0001-8058-4824

\section{Funding}

This work is financially supported by the ANR Bionanodetect project (ANR-15-CE39-0001). We are grateful to DGA for funding the Ph.D. thesis of G.G.

\section{Notes}

The authors declare no competing financial interest.

\section{ACKNOWLEDGMENTS}

The authors would like to thank Pierre Gibot for the krypton adsorption measurement and Thierry Dintzer and Dris Ihiawakrim for SEM and TEM images. We thank Laurent Schlur for his contribution on the detection tests.

\section{REFERENCES}

(1) Mahato, T. H.; Prasad, G. K.; Singh, B.; Acharya, J.; Srivastava, A. R.; Vijayaraghavan, R. Nanocrystalline Zinc Oxide for the Decontamination of Sarin. J. Hazard. Mater. 2009, 165, 928-932.

(2) Kassa, J. Review of Oximes in the Antidotal Treatment of Poisoning by Organophosphorus Nerve Agents. J. Toxicol. Clin. Toxicol. 2002, 40, 803-816.

(3) Sidell, F. R.; Borak, J. Chemical Warfare Agents: II. Nerve Agents. Ann. Emerg. Med. 1992, 21, 865-871.

(4) Kim, M. S.; Kim, G. W.; Park, T. J. A Facile and Sensitive Detection of Organophosphorus Chemicals by Rapid Aggregation of Gold Nanoparticles Using Organic Compounds. Biosens. Bioelectron. 2015, 67, 408-412.

(5) CDC - Index of Chemicals - NIOSH Publications and Products https://www.cdc.gov/niosh/idlh/intridl4.html (accessed Jan 9, 2019).

(6) Sun, Y.; Ong, K. Y. Detection Technologies for Chemical Warfare Agents and Toxic Vapors https://www.crcpress.com/DetectionTechnologies-for-Chemical-Warfare-Agents-and-Toxic-Vapors/SunOng/p/book/9781566706681 (accessed Jun 18, 2018).

(7) Pinnaduwage, L. A.; Gehl, A. C.; Allman, S. L.; Johansson, A.; Boisen, A. Miniature Sensor Suitable for Electronic Nose Applications. Rev. Sci. Instrum. 2007, 78, 55101.

(8) Seto, Y.; Kanamori-Kataoka, M.; Tsuge, K.; Ohsawa, I.; Iura, K.; Itoi, T.; Sekiguchi, H.; Matsushita, K.; Yamashiro, S.; Sano, Y.; et al. Sensitive Monitoring of Volatile Chemical Warfare Agents in Air by Atmospheric Pressure Chemical Ionization Mass Spectrometry with Counter-Flow Introduction. Anal. Chem. 2013, 85, 2659-2666.

(9) Zhao, R.; Jia, D.; Wen, Y.; Yu, X. Cantilever-Based Aptasensor for Trace Level Detection of Nerve Agent Simulant in Aqueous Matrices. Sens. Actuators, B 2017, 238, 1231-1239.

(10) Yang, Y.; Ji, H.-F.; Thundat, T. Nerve Agents Detection Using a $\mathrm{Cu}^{2+} /$ l-Cysteine Bilayer-Coated Microcantilever. J. Am. Chem. Soc. 2003, 125, 1124-1125.

(11) Zuo, G.; Li, X.; Li, P.; Yang, T.; Wang, Y.; Cheng, Z.; Feng, S. Detection of Trace Organophosphorus Vapor with a Self-Assembled Bilayer Functionalized $\mathrm{SiO}_{2}$ Microcantilever Piezoresistive Sensor. Anal. Chim. Acta 2006, 580, 123-127.

(12) Spitzer, D.; Cottineau, T.; Piazzon, N.; Josset, S.; Schnell, F.; Pronkin, S. N.; Savinova, E. R.; Keller, V. Bio-Inspired Nanostructured Sensor for the Detection of Ultralow Concentrations of Explosives. Angew. Chem., Int. Ed. 2012, 51, 5334-5338.

(13) Cottineau, T.; Pronkin, S. N.; Acosta, M.; Mény, C.; Spitzer, D.; Keller, V. Synthesis of Vertically Aligned Titanium Dioxide Nanotubes on Microcantilevers for New Nanostructured Micromechanical Sensors for Explosive Detection. Sens. Actuators, B 2013, 182, 489-497.

(14) Pinnaduwage, L. A.; Boiadjiev, V.; Hawk, J. E.; Thundat, T. Sensitive Detection of Plastic Explosives with Self-Assembled Monolayer-Coated Microcantilevers. Appl. Phys. Lett. 2003, 83, $1471-1473$

(15) Cai, S.; Li, W.; Xu, P.; Xia, X.; Yu, H.; Zhang, S.; Li, X. In Situ Construction of Metal-organic Framework (MOF) UiO-66 Film on 
Parylene-Patterned Resonant Microcantilever for Trace Organophosphorus Molecules Detection. Analyst 2019, 144, 3729-3735.

(16) Guo, S.; Xu, P.; Yu, H.; Li, X.; Cheng, Z. Hyper-Branch Sensing Polymer Batch Self-Assembled on Resonant Micro-Cantilevers with a Coupling-Reaction Route. Sens. Actuators, B 2015, 209, 943-950.

(17) Liu, Y.; Xu, P.; Yu, H.; Zuo, G.; Cheng, Z.; Lee, D.-W.; Li, X. Hyper-Branched Sensing Polymer Directly Constructed on a Resonant Micro-Cantilever for the Detection of Trace Chemical Vapor. J. Mater. Chem. 2012, 22, 18004-18009.

(18) Datskos, P. G.; Lavrik, N. V.; Sepaniak, M. J. Detection of Explosive Compounds with the Use of Microcantilevers with Nanoporous Coatings. Sens. Lett. 2003, 1, 25-32.

(19) Liu, G.; Lin, Y. Electrochemical Sensor for Organophosphate Pesticides and Nerve Agents Using Zirconia Nanoparticles as Selective Sorbents. Anal. Chem. 2005, 77, 5894-5901.

(20) Tudisco, C.; Betti, P.; Motta, A.; Pinalli, R.; Bombaci, L.; Dalcanale, E.; Condorelli, G. G. Cavitand-Functionalized Porous Silicon as an Active Surface for Organophosphorus Vapor Detection. Langmuir 2012, 28, 1782-1789.

(21) Chen, X.; Selloni, A. Introduction: Titanium Dioxide $\left(\mathrm{TiO}_{2}\right)$ Nanomaterials. Chem. Rev. 2014, 114, 9281-9282.

(22) Nakata, K.; Fujishima, A. $\mathrm{TiO}_{2}$ Photocatalysis: Design and Applications. J. Photochem. Photobiol., C 2012, 13, 169-189.

(23) Bai, J.; Zhou, B. Titanium Dioxide Nanomaterials for Sensor Applications. Chem. Rev. 2014, 114, 10131-10176.

(24) Wang, X.; Li, Z.; Shi, J.; Yu, Y. One-Dimensional Titanium Dioxide Nanomaterials: Nanowires, Nanorods, and Nanobelts. Chem. Rev. 2014, 114, 9346-9384.

(25) Cargnello, M.; Gordon, T. R.; Murray, C. B. Solution-Phase Synthesis of Titanium Dioxide Nanoparticles and Nanocrystals. Chem. Rev. 2014, 114, 9319-9345.

(26) Kathirvel, S.; Su, C.; Shiao, Y.-J.; Lin, Y.-F.; Chen, B.-R.; Li, W.R. Solvothermal Synthesis of $\mathrm{TiO}_{2}$ Nanorods to Enhance Photovoltaic Performance of Dye-Sensitized Solar Cells. Sol. Energy 2016, 132, $310-320$.

(27) Zhang, X.; Zhang, B.; Zuo, Z.; Wang, M.; Shen, Y. N/Si CoDoped Oriented Single Crystalline Rutile $\mathrm{TiO}_{2}$ nanorods for Photoelectrochemical Water Splitting. J. Mater. Chem. A 2015, 3, 1002010025 .

(28) Xie, Y.; Wei, L.; Wei, G.; Li, Q.; Wang, D.; Chen, Y.; Yan, S.; Liu, G.; Mei, L.; Jiao, J. A Self-Powered UV Photodetector Based on $\mathrm{TiO}_{2}$ Nanorod Arrays. Nanoscale Res. Lett. 2013, 8, 188.

(29) $\mathrm{Mu}$, Q.; Li, Y.; Wang, H.; Zhang, Q. Self-Organized $\mathrm{TiO}_{2}$ Nanorod Arrays on Glass Substrate for Self-Cleaning Antireflection Coatings. J. Colloid Interface Sci. 2012, 365, 308-313.

(30) Liu, B.; Aydil, E. S. Growth of Oriented Single-Crystalline Rutile $\mathrm{TiO}_{2}$ Nanorods on Transparent Conducting Substrates for Dye-Sensitized Solar Cells. J. Am. Chem. Soc. 2009, 131, 3985-3990.

(31) Mao, Y.; Ning, C.; Zhang, N.; Hu, Y.; Li, M.; Yang, H.; Chen, S.; Su, S.; Liang, E. Enhancing Photoelectrochemical Performance of $\mathrm{TiO}_{2}$ Nanowires through a Facile Acid Treatment Method. J. Electrochem. Soc. 2018, 165, H799-H803.

(32) Wu, J.; Lo, S.; Song, K.; Vijayan, B. K.; Li, W.; Gray, K. A.; Dravid, V. P. Growth of Rutile $\mathrm{TiO}_{2}$ nanorods on Anatase $\mathrm{TiO}_{2}$ thin Films on Si-Based Substrates. J. Mater. Res. 2011, 26, 1646-1652.

(33) Kumar, A.; Madaria, A. R.; Zhou, C. Growth of Aligned SingleCrystalline Rutile $\mathrm{TiO}_{2}$ Nanowires on Arbitrary Substrates and Their Application in Dye-Sensitized Solar Cells. J. Phys. Chem. C 2010, 114, 7787-7792.

(34) Liu, C.; Tang, J.; Chen, H. M.; Liu, B.; Yang, P. A Fully Integrated Nanosystem of Semiconductor Nanowires for Direct Solar Water Splitting. Nano Lett. 2013, 13, 2989-2992.

(35) Tang, D.; Cheng, K.; Weng, W.; Song, C.; Du, P.; Shen, G.; Han, G. $\mathrm{TiO}_{2}$ Nanorod Films Grown on Si Wafers by a NanodotAssisted Hydrothermal Growth. Thin Solid Films 2011, 519, 76447649.

(36) Qin, D.-D.; Bi, Y.-P.; Feng, X.-J.; Wang, W.; Barber, G. D.; Wang, T.; Song, Y.-M.; Lu, X.-Q.; Mallouk, T. E. Hydrothermal Growth and Photoelectrochemistry of Highly Oriented, Crystalline
Anatase $\mathrm{TiO}_{2}$ Nanorods on Transparent Conducting Electrodes. Chem. Mater. 2015, 27, 4180-4183.

(37) Cheng, H.; Ma, J.; Zhao, Z.; Qi, L. Hydrothermal Preparation of Uniform Nanosize Rutile and Anatase Particles. Chem. Mater. 1995, 7, 663-671.

(38) Burungale, V. V.; Satale, V. V.; Teli, A. M.; Kamble, A. S.; Kim, J. H.; Patil, P. S. Surfactant Free Single Step Synthesis of $\mathrm{TiO}_{2} 3-\mathrm{D}$ Microflowers by Hydrothermal Route and Its Photoelectrochemical Characterizations. J. Alloys Compd. 2016, 656, 491-499.

(39) Li, B.; Yu, D.; Zhang, S.-L. Raman Spectral Study of Silicon Nanowires. Phys. Rev. B 1999, 59, 1645-1648.

(40) Pérez León, C.; Kador, L.; Peng, B.; Thelakkat, M. Characterization of the Adsorption of Ru-Bpy Dyes on Mesoporous $\mathrm{TiO}_{2}$ Films with UV-Vis, Raman, and FTIR Spectroscopies. J. Phys. Chem. B 2006, 110, 8723-8730.

(41) Kanan, S. M.; Tripp, C. P. An Infrared Study of Adsorbed Organophosphonates on Silica: A Prefiltering Strategy for the Detection of Nerve Agents on Metal Oxide Sensors. Langmuir 2001, 17, 2213-2218.

(42) Khushalani, D.; Ozin, G. A.; Kuperman, A. Glycometallate Surfactants Part 2: Non-Aqueous Synthesis of Mesoporous Titanium, Zirconium and Niobium Oxides. J. Mater. Chem. 1999, 9, 1491-1500.

(43) Yang, J.; Puchberger, M.; Qian, R.; Maurer, C.; Schubert, U. Zinc(II) Complexes with Dangling Functional Organic Groups. Eur. J. Inorg. Chem. 2012, 2012, 4294-4300. 